\title{
Psychometric properties of the Patient Dignity Inventory in an acute psychiatric ward: an extension study of the preliminary validation
}

This article was published in the following Dove Press journal:

Neuropsychiatric Disease and Treatment

\author{
Rosaria Di Lorenzo' \\ Paola Ferri² \\ Carlotta Biffarella² \\ Giulio Cabri ${ }^{3}$ \\ Eleonora Carretti ${ }^{4}$ \\ Gabriella Pollutri ${ }^{5}$ \\ Ludovica Spattini ${ }^{5}$ \\ Cinzia Del Giovane ${ }^{6}$ \\ Harvey Max Chochinov ${ }^{7}$ \\ 'Psychiatric Intensive Treatment \\ Facility, Mental Health Department, \\ Azienda USL, Modena, Italy; \\ ${ }^{2}$ Department of Diagnostic, Clinical \\ and Public Health Medicine, University \\ of Modena and Reggio Emilia, Modena, \\ Italy; ${ }^{3}$ Service of Psychiatric Diagnosis \\ and Treatment, Mental Health \\ Department, Azienda USL, Modena, \\ Italy; ${ }^{4}$ School of Nursing, University \\ of Modena and Reggio Emilia, Italy; \\ ${ }^{5}$ School of Specialization in Pscyhiatry, \\ Faculty of Medicine, University of \\ Modena and Reggio Emilia, Italy; \\ ${ }^{6}$ Faculty of Medicine, Institute of \\ Primary Care (BIHAM), University of \\ Bern, Bern, Switzerland; ${ }^{7}$ Department \\ of Psychiatry, University of Manitoba, \\ Winnipeg, MB, Canada
}

Background: During the last decades, dignity has been an emerging issue in mental health since its ethical and therapeutic implications became known. This study is an extension of the preliminary validation of the Patient Dignity Inventory (PDI) in a psychiatric setting, originally designed for assessing perceived dignity in terminal cancer patients.

Methods: From October 21, 2015 to December 31, 2016, we administered the Italian PDI to all patients hospitalized in an acute psychiatric ward, who provided their consent and completed it at discharge $(\mathrm{n}=165)$. We performed Cronbach's alpha coefficient and principal factor analysis. We administered other scales concomitantly to analyze the concurrent validity of PDI. We applied stepwise multiple linear regression to identify the patients' demographic and clinical variables related to the PDI score.

Results: Our response rate was 93\%, with excellent internal consistency (Cronbach's alpha coefficient $=0.94$ ). The factorial analysis showed three factors with eigenvalue $>1$, which explained $>80 \%$ of total variance: 1 ) "loss of self-identity and anxiety for the future", 2) "concerns for social dignity and spiritual life", and 3) "loss of personal autonomy". The PDI and the three factor scores were positively and significantly correlated with the Hamilton Scales for Depression and Anxiety but not with other scale scores. Among patients' variables, "suicide risk" and "insufficient social and economic condition" were positively and significantly correlated with the PDI total score.

Conclusion: The PDI can be a reliable tool to assess patients' dignity perception in a psychiatric setting, which suggests that both social and clinical severe conditions are closely related to dignity loss.

Keywords: dignity perception in psychiatry, patient dignity inventory, patients hospitalized in an acute psychiatric ward, severe psychiatric diseases, suicide risk, insufficient social and economic condition

\section{Introduction}

\section{Dignity in mental health}

During the last decades, dignity has been an emerging issue in medicine and, in particular, in mental health. It embodies not only the fundamental human right to avoid discrimination, stigmatization, and marginalization, as World Health Organization ${ }^{1}$ stated but also represents a "means to recovery", in accordance with the Kogstad's study. ${ }^{2}$ Jacobson showed that the perception of dignity can explain the mutual relationship between health and human rights, suggesting that violation of dignity can result from asymmetrical relationships in vulnerable patients with disabling diseases. ${ }^{3}$

In mental health, dignity is closely associated with the concept of recovery, and a means of developing “new meaning and purpose in one's life as one grows beyond the
Correspondence: Rosaria Di Lorenzo Psychiatric Intensive Treatment Facility, Paul Harris Street, 175, 4II 22 Modena, Mental Department Mental Health, Azienda USL-Modena, Italy Email r.dilorenzo@ausl.mo.it 
catastrophic effects of mental illness" . Respecting patients' identity and dignity represents a fundamental element of the therapeutic approach to patients affected by mental diseases. ${ }^{2,5,6}$ "Listening to patients' views on the specific factors they consider useful to maintain their dignity" can preserve it, improving the therapeutic approach. ${ }^{7,8}$ Dignity and other four descriptive categories (security, participation, recovery and the care environment) emerged from the study of Schroeder et $\mathrm{al}^{9}$ who explored patients' perceptions of quality of care. Dignity and autonomy represent key targets of personalized patient care, a strategic approach to achieving quality outcomes, as defined by the Social Care Institute for Excellence. ${ }^{10}$ A person-centered approach in mental health consists of taking care of patient needs and respecting individual's preferences and rights. ${ }^{11}$

In accordance with authors who evaluated the experience of dignity among elderly adults with schizophrenia, the perception of self-dignity can be reduced by "ageism, stigma, discrimination, and alienation", whereas, in contrast, it can be supported by a therapeutic recovery-focused relationship. ${ }^{12}$

Care aimed at preserving dignity has been proposed as a "person-centered approach", which can reduce the psychosocial and existential burden related to chronic and severe illnesses, and, at the same time, improve the outcomes of treatment. ${ }^{13}$

\section{Dignity in an acute psychiatric ward}

The difficulties of maintaining dignity in acute mental health wards have been documented by many authors in different countries. $^{14-19}$

A qualitative study ${ }^{20}$ reported the experience of inpatient care as "a struggle for dignity in the face of discrimination and rejection". The Mental Health Act Commission's 2008 biennial report found conditions in acute psychiatric wards to be "tougher and scarier" than they were 10 years previously. $^{21}$

Campbell ${ }^{22}$ pointed out that the experience of a troubled hospitalization in a psychiatric ward could be as traumatic as the nervous breakdown that precipitated the hospitalization itself.

Environmental issues that can threaten dignity in acute wards include overcrowding and poor staffing (both in number and quality). Curtice and Exworthy ${ }^{23}$ identified environmental threats to dignity, including lack of privacy on mixed-gender wards and impoverished or unclean environments. Excessive bed demand and overoccupancy of acute psychiatric wards and facilities can further "exacerbate difficulties in maintaining the safety, dignity, and privacy of patients". ${ }^{21}$

\section{Patient dignity inventory}

The Patient Dignity Inventory (PDI) ${ }^{24}$ is one of the few available instruments for measuring dignity, developed by Chochinov in accordance with his model of dignity conserving care in the terminally ill patients. ${ }^{24,25}$ The PDI consists of 25 items aimed at investigating three primary domains of the model: 1) illness-related concerns, comprising level of independence and symptoms distress; 2) dignity conserving repertoire, consisting of dignity conserving perspectives and practices; and 3) social dignity inventory. ${ }^{26}$ This questionnaire was validated in many languages ${ }^{27-33}$ and was also applied in nononcologic settings, such as cardiology units ${ }^{34}$ and severely ill outpatient settings. ${ }^{35}$ The validation studies demonstrated similar good internal consistency and the existence of more than one factor, with the exception of the Italian study in oncology which evidenced only one factor. The preliminary validation study in an acute psychiatric ward highlighted three factors supported by all but two items of the PDI, which represented the main domains of dignity, excellent internal consistency and statistically significant positive correlation with the Hamilton Scales for both Depression and Anxiety. ${ }^{36}$

\section{Aims}

To extend the preliminary validation of PDI among patients hospitalized in an acute psychiatric ward and identify demographic and clinical variables related to PDI score.

\section{Methods \\ Study design}

Although PDI was originally designed for assessing perceived dignity-related distress in terminal cancer patients, its administration in a psychiatric setting can be justified by the high risk of loss of dignity potentially induced by both cancer illness and psychiatric disorders, especially if they are severe, chronic, disabling, and/or if they require hospitalization. Given the universality of dignity, the author of the PDI suggested its use in many different health contexts. ${ }^{24}$

We administered the Italian version of the PDI, initially validated in an oncology setting ${ }^{28}$ and successively modified for a psychiatric context in our preliminary validation study. ${ }^{36}$ The two slightly amended items were the following:

- No. 3: "physically distressing symptoms" was changed to "experiencing physically distressing symptoms (such as pain, shortness of breath, nausea) for example, adverse drug effects".

- No. 17: "concerns regarding spiritual life" was changed to "concern that my spiritual life is not meaningful". 
The PDI consists of 25 items that can be evaluated on a five-point scale ranging from "no problem", equivalent to the minimum score of 1 , to "an overwhelming problem", associated with the maximum score of 5 . Following the methodology of validation research, ${ }^{24,28}$ we concomitantly administered additional scales in order to evaluate the concurrent validity of the PDI main domains comparing them to standard validated measures. We used Hamilton Rating Scale for Depression (Ham-D), ${ }^{37}$ Hamilton Anxiety Rating Scale (Ham-A), ${ }^{38}$ and Global Assessment of Functioning (GAF).$^{39}$ Moreover, we evaluated the correlation of PDI with the Health of the Nation Outcome Scales (HoNOS), ${ }^{40}$ a questionnaire routinely used at admission and discharge of all patients in our psychiatric ward.

\section{Sampling strategies}

To determine an adequate sample size for performing factor analysis, we recruited five subjects per variable, according to "the rule of 5" in the subjects-to-variables ratio. ${ }^{41}$

We administered the PDI among patients hospitalized in the Service of Psychiatric Diagnosis and Treatment (SPDT) ward of a northern Italian town. The 15-bed SPDT, as required by Law 180 of 23/05/1978 (later included in Law 833 of 12/23/1978), is located in a General Hospital and serves patients from the related catchment areas with acute mental disorders requiring hospital care in voluntary and involuntary treatments.

We used the following criteria for collecting our sample:

- Inclusion criteria: patients hospitalized for $>72$ hours, able to understand the questionnaire, to complete it independently, and to give us their written informed consent.

- Exclusion criteria: patients hospitalized for $<72$ hours, affected by medium or severe intellectual disability, dementia or severe cognitive deterioration with MiniMental State Examination $<24,{ }^{42}$ minors, no knowledge of Italian language, previous administration of PDI.

\section{Working method and study period}

We chose to administer the PDI during the 3-day period before discharge in order to obtain the highest participation and study response from patients due to their clinical improvement compared with the moment of hospital admission. This timing of PDI administration also provided a sense of what impact hospitalization had had on patients in terms of dignity-related distress. At the moment of PDI administration, all patients were voluntarily hospitalized and freely participated in this study, after having provided their informed consent.
Data collection was conducted between October 21, 2015 and December 31, 2016.

Concurrent with the administration of the PDI, other scales described above were administered to each patient (HoNOS was also administered at the moment of admission as indicated by local guidelines).

We selected demographic and clinical variables of our sample from clinical records and information systems of our Mental Health Department, and, when necessary, from the patients' psychiatrists (Tables 1 and 2).

\section{Ethical considerations}

Data were collected after the Local Ethical Committee of Modena (3565 Protocol 173/15 Practice) and the Department of Mental Health Service approved this study. This research was conducted following the principles of the World Medical Association Declaration of Helsinki (1964) and according to good clinical practice criteria. Therefore, the written informed consent of each member of our sample was collected and, subsequently, e-mailed to the general practitioner indicating their patient was a participant in the present study.

Table I Demographic variables

\begin{tabular}{|c|c|c|c|}
\hline Variables & $\begin{array}{l}\text { Males, } \\
n=75(45 \%)\end{array}$ & $\begin{array}{l}\text { Females, } \\
\mathrm{n}=90(55 \%)\end{array}$ & $\begin{array}{l}\text { Total, } \\
n=165(100 \%)\end{array}$ \\
\hline \multicolumn{4}{|l|}{ Age (mean $\pm S D)$} \\
\hline Years & $43.29 \pm 14.96$ & $44.57 \pm 13.90$ & $43.89 \pm 14.42$ \\
\hline \multicolumn{4}{|l|}{ Nationality, n (\%) } \\
\hline Italian & $65(86)$ & $80(89)$ & $145(87)$ \\
\hline European extra-Italian & I (I) & $2(2)$ & $3(2)$ \\
\hline Extra-European & $9(12)$ & $8(9)$ & $17(11)$ \\
\hline \multicolumn{4}{|l|}{ Marital status, n (\%) } \\
\hline Single & $52(69)$ & $4 \mid(45)$ & $93(56)$ \\
\hline Married & $19(25)$ & $25(27)$ & $44(27)$ \\
\hline Divorced/widowed & $4(5)$ & $24(26)$ & $28(17)$ \\
\hline \multicolumn{4}{|l|}{ Schooling, n (\%) } \\
\hline Primary school & II (I5) & $10(11)$ & $21(13)$ \\
\hline Secondary school & $25(33)$ & $27(30)$ & $52(3 I)$ \\
\hline High school & $3 I(4 I)$ & $36(40)$ & $67(4 I)$ \\
\hline Degree & $8(\mathrm{II})$ & $17(19)$ & $25(15)$ \\
\hline \multicolumn{4}{|l|}{ Work activity, n (\%) } \\
\hline Employed & $25(33)$ & $34(38)$ & $59(36)$ \\
\hline Unemployed & $39(52)$ & $31(34)$ & $70(42)$ \\
\hline Retired & $6(8)$ & $15(17)$ & $21(13)$ \\
\hline Other & $5(7)$ & $10(11)$ & $15(9)$ \\
\hline \multicolumn{4}{|c|}{ Family and surrounding, n (\%) } \\
\hline Single & $16(21)$ & $31(34)$ & $47(28)$ \\
\hline Parental family & $39(52)$ & $22(24)$ & $61(37)$ \\
\hline Marital family & $17(23)$ & $34(38)$ & $5 I(3 \mid)$ \\
\hline $\begin{array}{l}\text { Community/ } \\
\text { residential facility }\end{array}$ & $3(4)$ & $3(3)$ & $6(4)$ \\
\hline \multicolumn{4}{|c|}{ Social and economic conditions, $\mathrm{n}(\%)$} \\
\hline Sufficient & $63(84)$ & $74(82)$ & I 37 (83) \\
\hline Insufficient & $12(16)$ & $16(17)$ & $28(17)$ \\
\hline
\end{tabular}


Table 2 Clinical variables

\begin{tabular}{|c|c|c|c|}
\hline Variables & $\begin{array}{l}\text { Males, } \\
n=75(45 \%)\end{array}$ & $\begin{array}{l}\text { Females, } \\
n=90(55 \%)\end{array}$ & $\begin{array}{l}\text { Total, } n=165 \\
(100 \%)\end{array}$ \\
\hline \multicolumn{4}{|l|}{ Psychiatric illness duration (mean $\pm S D$ ) } \\
\hline Years & $9.35 \pm 9.55$ & $9.80 \pm 9.08$ & $9.58 \pm 9.28$ \\
\hline \multicolumn{4}{|l|}{ Previous psychiatric hospitalizations, $\mathrm{n}(\%)$} \\
\hline First psychiatric hospitalization & $3 I(4 I)$ & $27(30)$ & $58(35)$ \\
\hline One or more previous psychiatric hospitalizations & $44(59)$ & $63(70)$ & $107(65)$ \\
\hline \multicolumn{4}{|l|}{ Psychiatric diagnosis at discharge (ICD-9CM), n (\%) } \\
\hline Schizophrenic and other psychotic disorders & $30(40)$ & $39(43)$ & $69(42)$ \\
\hline Bipolar disorders, manic episode & $16(21)$ & $21(23)$ & $37(22)$ \\
\hline Personality disorders & $18(24)$ & $18(20)$ & $36(22)$ \\
\hline Anxious disorders and dysthymia & $7(9)$ & $6(7)$ & $13(8)$ \\
\hline Organic psychosis & $2(3)$ & $4(4)$ & $6(4)$ \\
\hline Other & $2(3)$ & $2(2)$ & $4(2)$ \\
\hline \multicolumn{4}{|l|}{ Organic comorbidity, n (\%) } \\
\hline Present & $29(38)$ & $34(37)$ & $63(38)$ \\
\hline Absent & $46(61)$ & $56(63)$ & $102(62)$ \\
\hline \multicolumn{4}{|l|}{ Substance abuse, $\mathrm{n}(\%)$} \\
\hline Present & $30(40)$ & $20(23)$ & $50(30)$ \\
\hline Absent & $45(60)$ & $70(77)$ & $115(70)$ \\
\hline \multicolumn{4}{|l|}{ Duration of hospitalization $(\mathrm{m} \pm \mathrm{SD})$} \\
\hline Days & $16.04 \pm 20.94$ & $16.16 \pm 13.40$ & $15.96 \pm 17.22$ \\
\hline \multicolumn{4}{|l|}{ State of hospitalization, $\mathrm{n}(\%)$} \\
\hline Involuntary treatment & $28(37)$ & $47(52)$ & $78(47)$ \\
\hline Voluntary treatment & $50(66)$ & $40(44)$ & $87(53)$ \\
\hline \multicolumn{4}{|l|}{ Destination at discharge, $\mathrm{n}(\%)$} \\
\hline Home & $45(60)$ & $59(65)$ & $104(63)$ \\
\hline Transfer to private hospital & $24(32)$ & $25(28)$ & $49(30)$ \\
\hline Transfer to community or residential facilities & $6(8)$ & $6(7)$ & $12(7)$ \\
\hline \multicolumn{4}{|c|}{ Need for supplementary laboratory and clinical tests, $n(\%)$} \\
\hline Present & $37(49)$ & $39(43)$ & $76(46)$ \\
\hline Absent & $38(51)$ & $51(57)$ & $89(54)$ \\
\hline \multicolumn{4}{|l|}{ Drug administration, $\mathrm{n}(\%)$} \\
\hline Oral & $50(47)$ & $56(42)$ & $106(64)$ \\
\hline Parental or more than one route & $25(53)$ & $34(58)$ & $59(36)$ \\
\hline \multicolumn{4}{|c|}{ Outpatient service therapeutic-rehabilitative programs, n (\%) } \\
\hline Present & $69(92)$ & $80(89)$ & $149(90)$ \\
\hline Absent & $5(7)$ & $10(11)$ & $15(10)$ \\
\hline \multicolumn{4}{|l|}{ Suicide risk, n (\%) } \\
\hline Present & $18(24)$ & $17(19)$ & $35(21)$ \\
\hline Absent & $57(76)$ & $73(81)$ & $130(79)$ \\
\hline
\end{tabular}

Abbreviation: ICD-9CM, International Classification of Diseases, 9th Revision, Clinical Modification.

\section{Statistical analysis}

Descriptive statistical analysis was performed for demographic and clinical variables: mean \pm SD for continuous data and percentages for categorical data. The admission and discharge HoNOS scores were compared by paired $t$-test. The PDI content and face validity were assessed before the administration of the questionnaire as reported in the preliminary research. ${ }^{36}$ The content validity was discussed among the researchers and the face validity was initially assessed by the first 20 patients of our sample in order to evaluate their capacity to understand and answer the questionnaire. We investigated the internal consistency of the PDI to assess the structural validity and explored its dimensions by factor analysis.

The internal consistency of the PDI was evaluated by Cronbach's alpha coefficient. We have performed the principal factor analysis. ${ }^{43}$ The factor patterns were computed using the squared multiple correlations as estimates of the communality, followed by the orthogonal varimax rotation. ${ }^{44}$ The factors highlighted by the orthogonal rotation were selected according to eigenvalue $>1$ for each factor (Kaiser's criterion), ${ }^{45}$ later confirmed by the scree plot graphical feedback. The items with factor loadings $>0.40$ on a given dimension were identified as good indicators of each factor. 
We applied the oblique rotation of the factors (promax), which allowed the assessment of the factors' interdependence, as sensitivity analysis. ${ }^{46}$

To assess the adequacy of our sample for factor analysis, we applied the Kaiser-Meyer-Olkin measure, which evaluates the sampling adequacy, and the Bartlett's test of sphericity, which tests whether the data come from a normal distribution with zero covariance. ${ }^{47}$

Similarly, to examine internal consistency and concurrent validity of each factor previously identified, we calculated the Cronbach's alpha coefficient for each factor and analyzed the correlation with all other scale scores. We analyzed the PDI concurrent validity by means of the correlation with all other scale scores (Ham-A, Ham-D, GAF, HoNOS; Spearman's rho). We used a backward stepwise multiple linear regression to identify the demographic and clinical variables correlated with the PDI score (dependent variable). Variables with a $p$-value $>0.05$ were removed from the model. ${ }^{48}$ The same model was applied to evaluate the correlation between the sum of the items that loaded onto the identified factors and other selected variables.

Data were analyzed using STATA Version $12.60 .^{49}$

\section{Results}

\section{Sample section}

In our study, we obtained a response of $93 \%$ since only 12 of 177 individuals to whom the PDI questionnaire was proposed $(7 \%)$ did not agree to participate for various reasons.

The demographic variables of the 165 patients who participated in the study, 90 females (55\%) and 75 males (45\%), are shown in Table 1.

Regarding clinical variables, shown in Table 2, our patients suffered from serious psychiatric diseases, according to International Classification of Diseases, 9th Revision, Clinical Modification; ${ }^{50} 47 \%$ of the sample were hospitalized in compulsory state, according to Italian Law 180, with an average length of 3.36 days under compulsory treatment; suicidal risk, routinely confirmed on the basis of a clinical evaluation when patients were admitted, was detected in $21 \%$ of our sample.

Regarding the administration of the PDI, almost all patients in the sample stated that they did not encounter any difficulty in understanding the questionnaire, which they completed independently.

\section{PDI validation section}

The total score obtained on the PDI averaged 48.58 $( \pm 21.11 \mathrm{SD})$ as shown in Table 3 . All items in the questionnaire, rated on a scale from 1 to 5 , presented an average score $<3$. The 25 items of the PDI questionnaire showed excellent internal consistency, with a Cronbach's alpha coefficient $\geq 0.93$ (Table 3 ).

Our factorial analysis yielded three initial factors that explained $>80 \%$ of the cumulative variance of the model, with eigenvalue $>1$ according to Kaiser's criterion (Table 4). The weight of three factors was graphically confirmed by scree plot (Figure 1). Orthogonal rotation put in evidence the items underlying the three factors with their factor loadings and their uniqueness (Table 5).

From our model, item no. 3 "experiencing physically distressing symptoms (such as pain, shortness of breath, nausea) as drug adverse effects" and item no. 10 "not being able to continue with my usual routines" were excluded because they had factor loading $<0.40$ and uniqueness $>0.70$ (Table 5). Each of the three factors showed a good internal consistency: for Factor 1, "loss of self-identity and anxiety for the future" (Cronbach's alpha coefficient=0.93); Factor 2: "concerns for social dignity and spiritual life" (Cronbach's alpha coefficient=0.76); and Factor 3: "loss of personal autonomy" (Cronbach's alpha coefficient $=0.81$; see Table 5 for details regarding factor loading).

We obtained a value of 0.89 at the Kaiser-MeyerOlkin test (range between 0 and 1), which permitted us to define our sample "meritorious" since it was numerically adequate for factor analysis. Bartlett's test of sphericity (chi-square=2,299.6; $d f=300 ; p<0.001$ ) showed that items were not intercorrelated.

The oblique rotation revealed that the same three main factors were positively and partially related to each other (Factors 1 and 2: 0.66; Factors 1 and 3: 0.55; Factors 2 and 3: 0.54).

Ham-D and Ham-A scale scores showed that participants suffered predominantly from mild anxiety and depressive symptoms. The statistically significant correlation between the Ham-D and Ham-A scales scores and the overall score of the PDI showed the concurrent validity of the questionnaire (Table 6). No statistically significant correlation was obtained with the scores of the other scales administered. The HoNOS score at discharge was statistically significantly different from that obtained at admission, indicating an overall clinical improvement of patients at the time of discharge (Table 6).

\section{Correlation between PDI score and demographic and clinical variables}

At our multiple linear regression analysis, according to the stepwise model, only some variables were statistically 
Table 3 PDI score, inter-item correlations, and Cronbach's alpha coefficient in our sample

\begin{tabular}{|c|c|c|c|c|c|}
\hline \multicolumn{2}{|c|}{ PDI items } & \multirow{2}{*}{$\begin{array}{l}\text { Mean } \pm \text { SD } \\
1.57 \pm 1.13\end{array}$} & \multirow{2}{*}{$\begin{array}{l}\text { Min-max } \\
\mathrm{I}-5\end{array}$} & \multirow{2}{*}{$\begin{array}{l}\text { Item-test, } \\
\text { correlation }\end{array}$} & \multirow{2}{*}{$\begin{array}{l}\text { Cronbach's } \\
\text { alpha coefficient } \\
0.94\end{array}$} \\
\hline 1 & $\begin{array}{l}\text { Not being able to carry out tasks associated with daily living (eg, washing } \\
\text { myself, getting dressed) }\end{array}$ & & & & \\
\hline 2 & $\begin{array}{l}\text { Not being able to attend to my bodily functions independently (eg, needing } \\
\text { assistance with toileting-related activities) }\end{array}$ & $1.39 \pm 0.93$ & $1-5$ & 0.49 & 0.94 \\
\hline $3^{\mathrm{a}}$ & $\begin{array}{l}\text { Experiencing physically distressing symptoms (such as pain, shortness of } \\
\text { breath, nausea) as drug adverse effects }\end{array}$ & $1.93 \pm 1.17$ & $\mathrm{I}-5$ & 0.37 & 0.94 \\
\hline 4 & Feeling that how I look to others has changed significantly & $1.82 \pm 1.19$ & $\mathrm{I}-5$ & 0.56 & 0.94 \\
\hline 5 & Feeling depressed & $2.35 \pm 1.47$ & $\mathrm{I}-5$ & 0.68 & 0.94 \\
\hline 6 & Feeling anxious & $2.26 \pm 1.37$ & $\mathrm{I}-5$ & 0.67 & 0.94 \\
\hline 7 & Feeling uncertain about my illness and treatment & $1.96 \pm 1.22$ & $\mathrm{I}-5$ & 0.7 & 0.94 \\
\hline 8 & Worrying about my future & $2.53 \pm 1.47$ & $\mathrm{I}-5$ & 0.66 & 0.94 \\
\hline 9 & Not being able to think clearly & $1.89 \pm 1.28$ & $\mathrm{I}-5$ & 0.76 & 0.94 \\
\hline 10 & Not being able to continue with my usual routines & $2.28 \pm 1.44$ & $\mathrm{I}-5$ & 0.57 & 0.94 \\
\hline 11 & Feeling like I am no longer who I was & $1.79 \pm 1.20$ & $\mathrm{I}-5$ & 0.68 & 0.94 \\
\hline 12 & Not feeling worthwhile or valued & $1.88 \pm 1.24$ & $\mathrm{I}-5$ & 0.71 & 0.94 \\
\hline 13 & Not being able to carry out important roles (eg, spouse, parent) & $2.07 \pm 1.49$ & $\mathrm{I}-5$ & 0.72 & 0.94 \\
\hline 14 & Feeling that life no longer has meaning or purpose & $1.91 \pm 1.32$ & $\mathrm{I}-5$ & 0.75 & 0.94 \\
\hline 15 & $\begin{array}{l}\text { Feeling that I have not made a meaningful and lasting contribution during } \\
\text { my lifetime }\end{array}$ & $2.01 \pm 1.31$ & $1-5$ & 0.79 & 0.94 \\
\hline 16 & Feeling I have "unfinished business" (eg, things left unsaid or incomplete) & $2.34 \pm 1.34$ & $\mathrm{I}-5$ & 0.65 & 0.94 \\
\hline $17^{a}$ & Concern that my spiritual life is not meaningful & $1.60 \pm 1.08$ & $\mathrm{I}-5$ & 0.53 & 0.94 \\
\hline 18 & Feeling that I am a burden to others & $2.20 \pm 1.49$ & $\mathrm{I}-5$ & 0.68 & 0.94 \\
\hline 19 & Feeling that I do not have control over my life & $2.14 \pm 1.43$ & $\mathrm{I}-5$ & 0.83 & 0.94 \\
\hline 20 & Feeling that my illness and care needs have reduced my privacy & $1.97 \pm 1.25$ & $\mathrm{I}-5$ & 0.59 & 0.94 \\
\hline 21 & Not feeling supported by my community of friends and family & $1.99 \pm 1.32$ & $\mathrm{I}-5$ & 0.6 & 0.94 \\
\hline 22 & Not feeling supported by my health care providers & $1.59 \pm 1.05$ & $\mathrm{I}-5$ & 0.44 & 0.94 \\
\hline 23 & Feeling like I am no longer able to mentally "fight" the challenges of my illness & $1.78 \pm 1.18$ & $\mathrm{I}-5$ & 0.74 & 0.94 \\
\hline 24 & Not being able to accept the way things are & $2.01 \pm 1.34$ & $\mathrm{I}-5$ & 0.71 & 0.94 \\
\hline 25 & Not being treated with respect or understanding by others & $1.91 \pm 1.28$ & $\mathrm{I}-5$ & 0.66 & 0.94 \\
\hline Tota & & $48.58 \pm 21.11$ & $25-125$ & - & 0.94 \\
\hline
\end{tabular}

Note: altems modified.

Abbreviation: PDI, Patient Dignity Inventory.

significantly correlated with the total score of the PDI: "suicide risk", "insufficient social and economic condition", "no need for supplementary laboratory and clinical tests" (Table 7). Applying the stepwise multiple linear regression model to the correlation between our three factors and other variables, we highlighted the following:

- Factor 1 was statistically significantly positively correlated with "suicide risk", "insufficient social and

Table 4 Initial factor loading for the PDI

\begin{tabular}{llll}
\hline Initial factors & Eigenvalues & Proportion & Cumulative \\
\hline Factor I & 10.54 & 0.69 & 0.69 \\
Factor 2 & 1.16 & 0.07 & 0.76 \\
Factor 3 & 1.00 & 0.06 & 0.83 \\
Factor 4 & 0.79 & 0.05 & 0.88 \\
Factor 5 & 0.66 & 0.04 & 0.93 \\
Factor 6 & 0.52 & 0.03 & 0.96 \\
Factor 7 & 0.44 & 0.02 & 0.99 \\
Factor 8 & 0.38 & 0.02 & 1.01 \\
Factor 9 & 0.31 & 0.02 & 1.04 \\
Factor 10 & 0.24 & 0.01 & 1.05
\end{tabular}

Note: The 10 largest initial eigenvalues of the I-10 Factors are summarized. Abbreviation: PDI, Patient Dignity Inventory. economic condition", "no need for supplementary laboratory and clinical tests", and with "the marital status of widowed/divorced".

- Factor 2 was statistically significantly negatively correlated with "absent outpatient service programs" and positively

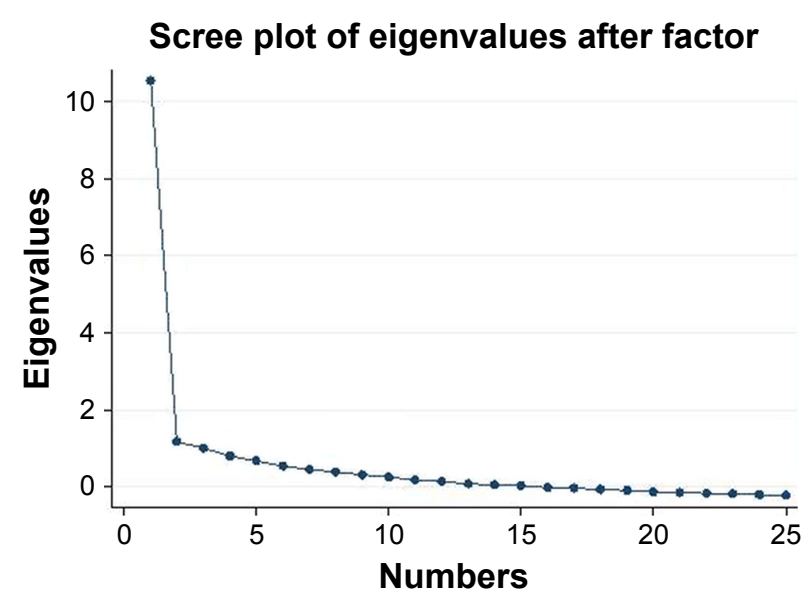

Figure I Scree plot of the factorial analysis. 
Table 5 Rotated factor loadings and uniqueness in the PDI factorial analysis

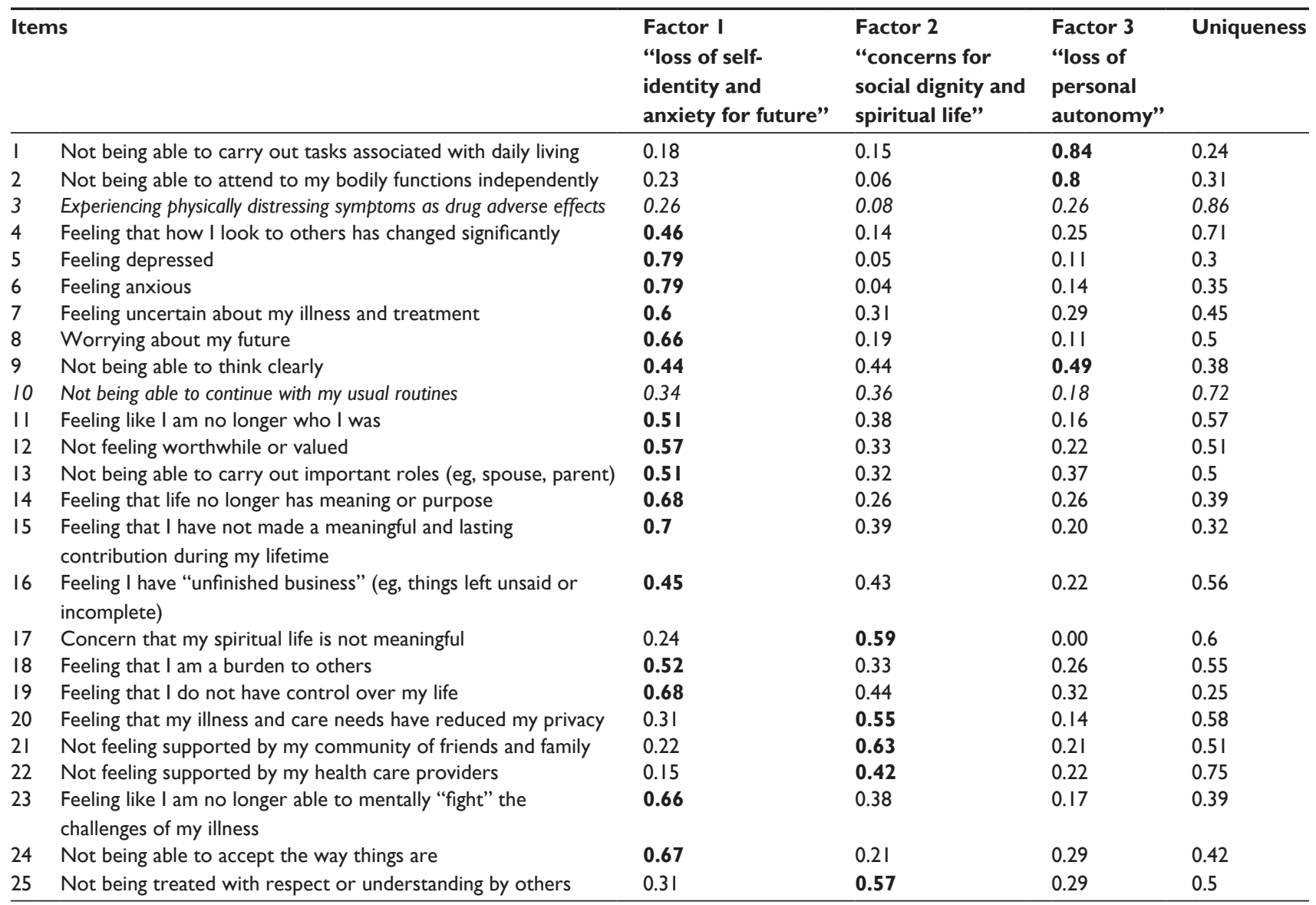

Note: The items excluded are in italics and the items loading factors are in bold.

Abbreviation: PDI, Patient Dignity Inventory.

with "insufficient social and economic condition" and "no need for supplementary laboratory and clinical tests".

- Factor 3 was statistically significantly positively correlated with "age", although with a low coefficient, and with "being hospitalized in psychiatry for the first time" (Table 7).

\section{Discussion}

Our research analyzed the psychometric properties of PDI, developed and validated for cancer patients, among patients hospitalized in a psychiatric ward. Although neoplastic diseases and mental disorders are pathologically very distant, both conditions can lead to drastic changes in patients'

Table 6 Correlations of PDI and three factors with scale scores

\begin{tabular}{|c|c|c|c|c|}
\hline Scale & PDI $(m=49.10 \pm 20.9$ SD) & Factor I (m=3I.0I $\pm \mid 4.65 \mathrm{SD})$ & Factor $2(\mathrm{~m}=9.04 \pm 4.32 \mathrm{SD})$ & Factor $3(m=4.84 \pm 2.85 \mathrm{SD})$ \\
\hline \multicolumn{5}{|l|}{$\mathrm{GAF}(\operatorname{mean} \pm \mathrm{SD})$} \\
\hline $71.67 \pm 15.04$ & NS & NS & NS & NS \\
\hline \multicolumn{5}{|c|}{ Ham-D (mean $\pm S D)$} \\
\hline $14.54 \pm 8.13$ & $\begin{array}{l}\text { Spearman's rho }=0.3439 \\
(p<0.000 \mathrm{I})\end{array}$ & $\begin{array}{l}\text { Spearman's rho }=0.3526 \\
(p<0.000 \mathrm{I})\end{array}$ & $\begin{array}{l}\text { Spearman's rho }=0.2408 \\
(p=0.0049)\end{array}$ & $\begin{array}{l}\text { Spearman's rho }=0.278 \mathrm{I} \\
(p=0.00 \mathrm{II})\end{array}$ \\
\hline \multicolumn{5}{|c|}{ Ham-A (mean $\pm S D)$} \\
\hline $10.44 \pm 7.91$ & $\begin{array}{l}\text { Spearman's rho }=0.3224 \\
(p<0.000 \mathrm{I})\end{array}$ & $\begin{array}{l}\text { Spearman's rho }=0.34 \mathrm{I} 3 \\
(p=0.000 \mathrm{I})\end{array}$ & $\begin{array}{l}\text { Spearman's rho }=0.2448 \\
(p=0.042)\end{array}$ & $\begin{array}{l}\text { Spearman's rho }=0.2059 \\
(p=0.0166)\end{array}$ \\
\hline \multicolumn{5}{|c|}{ HoNOS at admission (mean \pm SD) } \\
\hline $24.99 \pm 8.45$ & NS & NS & NS & NS \\
\hline \multicolumn{5}{|c|}{ HoNOS at discharge (mean \pm SD) } \\
\hline $17.80 \pm 6.8^{\mathrm{a}}$ & NS & NS & NS & NS \\
\hline
\end{tabular}

Notes: aHoNOS at admission vs HoNOS at discharge, $p<0.001$, $t=14$.19, paired $t$-test. Factor I: "Loss of self-identity and anxiety for future"; Factor 2 : "Concerns for social dignity and spiritual life"; Factor 3: "Loss of personal autonomy".

Abbreviations: GAF, Global Assessment of Functioning; Ham-A, Hamilton Anxiety Rating Scale; Ham-D, Hamilton Rating Scale for Depression; HoNOS, Health of the Nation Outcome Scales; PDI, Patient Dignity Inventory; NS, not significant. 
Table 7 Variables related to PDI and Factors I, 2, and 3 (stepwise multiple linear regression)

\begin{tabular}{|c|c|c|c|c|}
\hline $\begin{array}{l}\text { Variable }^{a} \text { (reference } \\
\text { category) }\end{array}$ & Coefficient & $\begin{array}{l}\text { Standard } \\
\text { error }\end{array}$ & $95 \% \mathrm{Cl}$ & $p$-value \\
\hline \multicolumn{5}{|l|}{ PDI score } \\
\hline \multicolumn{5}{|c|}{ Social and economic conditions (sufficient) } \\
\hline Insufficient & 13.11 & 4.19 & 4.83 to 21.38 & 0.002 \\
\hline \multicolumn{5}{|l|}{ Suicidal risk (absent) } \\
\hline Present & 11.07 & 3.82 & 3.53 to $18.6 \mid$ & 0.004 \\
\hline \multicolumn{5}{|c|}{ Need for clinical and instrumental test (present) } \\
\hline Absent & 7.99 & 3.12 & 1.83 to 14.15 & 0.011 \\
\hline \multicolumn{5}{|l|}{ Factor I } \\
\hline \multicolumn{5}{|c|}{ Social and economic conditions (sufficient) } \\
\hline Insufficient & 7.19 & 2.84 & 1.58 to 12.80 & 0.012 \\
\hline \multicolumn{5}{|l|}{ Suicidal risk (absent) } \\
\hline Present & 6.96 & 2.54 & 1.93 to 11.99 & 0.007 \\
\hline \multicolumn{5}{|c|}{ Need for clinical and instrumental test (present) } \\
\hline Absent & 4.77 & 1.99 & 0.83 to 8.70 & 0.018 \\
\hline \multicolumn{5}{|l|}{ Marital status (single) } \\
\hline Divorced/widowed & 5.55 & 2.73 & 0.16 to 10.94 & 0.044 \\
\hline \multicolumn{5}{|l|}{ Factor 2} \\
\hline \multicolumn{5}{|c|}{ Social and economic conditions (sufficient) } \\
\hline Insufficient & 2.74 & 0.66 & 1.44 to 4.04 & $<0.001$ \\
\hline \multicolumn{5}{|c|}{ Need for supplementary laboratory and clinical tests (present) } \\
\hline No need & 1.13 & 0.48 & 0.19 to 2.07 & 0.019 \\
\hline \multicolumn{5}{|c|}{ Outpatient service therapeutic-rehabilitative programs (present) } \\
\hline Absent & -2.24 & 0.85 & -3.91 to -0.56 & 0.009 \\
\hline \multicolumn{5}{|l|}{ Factor 3} \\
\hline Age (years) & 0.032 & 0.015 & 0.00 to 0.06 & 0.036 \\
\hline \multicolumn{5}{|c|}{ Number of previous psychiatric hospitalizations (one or more than one) } \\
\hline First psychiatric hospitalization & 1.12 & 0.45 & 0.24 to 2.01 & 0.013 \\
\hline
\end{tabular}

Notes: "Only the statistically significant variables are reported. Factor I: "Loss of self-identity and anxiety for future"; Factor 2: "Concerns for social dignity and spiritual life"; Factor 3: "Loss of personal autonomy".

Abbreviation: PDI, Patient Dignity Inventory.

lives, with high risk of loss of dignity. Both pathologies are often chronic and require long-term therapies and recurrent admissions for exacerbations and/or complications. In addition, the hospitalization, by itself, can induce a further risk of behavioral regression, as many researchers have pointed out. ${ }^{51-53}$

The patients in our sample, although suffering from severe and chronic diseases, showed good response rate (93\%), suggesting that the questionnaire was easy to understand as well as to fill in. Its content aroused great interest among patients, who showed a clear understanding of the meaning of dignity. Administering the PDI close to discharge may have enhanced acceptance, given that patients clinically and functionally improved as evidenced by the HoNOS and GAF scale scores, respectively.

The present study confirms our preliminary validation results and all previous studies in many different settings, ${ }^{18-19,21}$ suggesting the universality of the dignity theme in health care contexts and the reliability of the PDI questionnaire in detecting this dimension of patient experience.
Similar to our previous study, this second factorial analysis showed that dignity is shaped by three dimensions that account for $>80 \%$ of the variance. This result, which suggests that more than one existential, psychological, and/or social dimension can influence the perception of dignity, is consistent with all other validation studies, ${ }^{24,30-33}$ with the exception of the first Italian validation study, ${ }^{28}$ which identified only one factor. In particular, Factor 1, "loss of selfidentity and anxiety for the future", consisted of the greatest number of items with the highest internal consistency. It included items related to maintaining self-identity and items that investigate anxiety and uncertainty for future (items 4, 5, 6,7 , and 11). Our three factors loaded all items except two: items 3 and 10. This result confirms the lack of specificity of item no. 3 , relating to the physical complications of the disease (which we changed to "tolerate drug side effects"), probably because somatic symptoms among psychiatric diseases do not constitute a therapeutic priority, although they may be a comorbidity. In contrast to the preliminary study, item 10 , "not being able to continue the usual activities", did not load 
any factor in this extension study. We can hypothesize that the lack of routine daily activities differs in some qualitative way from that experienced by terminally ill patients.

Our three-factor model largely overlaps with the three major dignity categories identified by Chochinov et al. ${ }^{24}$ Moreover, our factorial analysis is consistent with Jacobson's notion of the "human and social" dimensions of dignity, which is formed by the interaction between individuals and society, with its culture and traditions. ${ }^{54}$

In our sample, Factor 1 obtained the highest score, indicating that the individual's dignity can be one of the most difficult ethical and psychological dimensions to preserve when an individual is suffering from a severe psychiatric disease. The data appear understandable in light of the fact that our sample consisted of patients hospitalized in acute psychiatric crisis: for about one-third of them, this was a first hospitalization experience and $47 \%$ had been admitted in a compulsory state. The experience of hospitalization, especially in a psychiatric environment, can represent a dramatic break from previous living conditions, as noted by many authors. ${ }^{22,52,53}$ This condition can make the individual more vulnerable, undermining the sense of self and, at the same time, fostering feelings of anxiety and depression. Especially in an acute psychiatric ward, the limitation of living space, although often necessary to contain the most serious pathologies, deprives patients of liberty and privacy.

In our sample, the PDI score was significantly associated with the Hamilton scales for depression and anxiety, suggesting that the PDI maps well onto dimensions of depression and anxiety. This and the preliminary study results provide concurrent validity to the PDI applied in psychiatry setting. It should be emphasized that under severe anxiety and depression, patients show more marked problems in perception of dignity, as evidenced by Rullàn et $\mathrm{al}^{30}$ who reported high scores in PDI among patients with anxious depressive disorders. Nevertheless, we can infer that these symptoms were related not only to a specific psychiatric diagnosis (most of our patients suffered from different kinds of diseases), but also to the hospitalization, which can induce anxiety and depressive feelings. As patients' self-perception of dignity is an important treatment goal to maintain during therapeutic work, clinicians would likely benefit from the findings in the current study, where the PDI was found to be a valid and reliable assessment tool.

Only a few variables were statistically significantly related to the PDI score in our multiple linear regression model, in particular "insufficient social and economic condition" among demographic variables, "suicide risk" and "no need for supplementary laboratory and clinical tests", among clinical ones. This result suggests that dignity among patients hospitalized in psychiatry can be undermined by both clinical and social factors. In particular, feelings of uncertainty for precarious economic conditions as well as feelings of hopelessness and helplessness associated with suicidal thoughts can be strong detrimental factors for dignity preservation. The association between the "no need for supplementary laboratory and clinical examinations" and the risk of compromised dignity could indicate that psychiatric illness alone can represent a risk of loss of dignity, even without organic comorbidity, probably for psychological suffering, social maladjustment, and stigma.

The statistically significant correlations between our three factors and variables further suggest the weight of this association and, at the same time, the specificity of the psychological dimensions that support the three factors. Factor 1 was statistically significantly associated not only with the three abovementioned variables, but also with the demographic variable "being widowed or divorced", a condition which can strongly damage the dignity of self-identity under vulnerable condition of illness, due to solitude and feelings of abandonment. Factor 2, "concerns for social dignity and spiritual life", was further confirmed by the statistically significant correlation with "insufficient social and economic condition". The risk of losing dignity in case of reduced independence level, identified by Factor 3, "loss of personal autonomy", was related to the increase in age, which is consistent with the literature, ${ }^{55}$ and to the first psychiatric hospitalization experience, which can represent a dramatic disruption in life habits and expectations. ${ }^{20,21}$

Our survey confirmed that PDI is an easily understood and applied tool, regardless of the level of education, useful to quantify the subjective experience of dignity during hospitalization, as recently highlighted by some authors, ${ }^{56}$ also in a psychiatric setting. The questionnaire, given in the days preceding discharge, can help professionals reflect on the care they have offered and its impact. At the same time, the PDI permits a better understanding of how patients experience illness and care, promoting a more empathetic therapeutic relationship. PDI administration was appreciated by our patients, who interpreted it as a sign of professional interest in them, which represents the foundation of all therapeutic approaches and conditions necessary for positive outcomes. ${ }^{57}$

\section{Limitations}

This study presents many limitations regarding settings, sample size, and the wide variety of diseases suffered by 
our patients. The relatively small increase in sample size of this study, which is an extension of the preliminary validation research, is a particular limitation. Another problematic issue throughout the study is the limited generalizability of the findings, as the sample consisted of a cohort of Italian patients hospitalized in an inpatient psychiatric setting.

\section{Conclusion}

This extension study replicates previous preliminary results and adds new information regarding the variables that can influence the perception of dignity in a psychiatric setting: the clinical and social conditions of greatest seriousness, such as risk of suicide as well as social and economic disadvantage, can be factors closely related to loss of dignity among patients hospitalized in a psychiatric ward.

In the light of our findings, we conclude by saying that the PDI can be a reliable and valuable tool for discovering the subjective experience of dignity among patients hospitalized in a psychiatric ward, helping us to understand the various universal psychological dimensions that contribute to shape it: the area of the self, the social role, and the level of independence.

\section{Acknowledgments}

The authors specially thank the patients who participated in this research and thanks are due to Orianna Raggioli who carefully revised this paper.

\section{Author contributions}

All authors contributed toward data analysis, drafting and revising the paper and agree to be accountable for all aspects of the work.

\section{Disclosure}

The authors report no conflicts of interest in this work.

\section{References}

1. WHO World Health Organization: World Mental Health Day 2015. Dignity and Mental Health [homepage on the Internet]; 2015. Available from: http://www.who.int/mental_health/world-mental-health-day/2015/ en/. Accessed September 30, 2017.

2. Kogstad RE. Protecting mental health clients' dignity - the importance of legal control. Int J Law Psychiatry. 2009;32(6):383-391.

3. Jacobson N. Dignity violation in health care. Qual Health Res. 2009; 19(11):1536-1547.

4. Anthony WA. Recovery from mental illness: the guiding vision of the mental health service system in the 1990s. Psychosoc Rehabil J. 1993; 16(4):11-23.

5. Lindwall L, Boussaid L, Kulzer S, Wigerblad A. Patient dignity in psychiatric nursing practice. J Psychiatr Ment Health Nurs. 2012; 19(7):569-576
6. Kleintjes S, Lund C, Swartz L. Barriers to the participation of people with psychosocial disability in mental health policy development in South Africa: a qualitative study of perspectives of policy makers, professionals, religious leaders and academics. BMC Int Health Hum Rights. 2013;13:17.

7. Ferri P, Muzzalupo J, Di Lorenzo R. Patients' perception of dignity in an Italian general hospital: a cross-sectional analysis. BMC Health Serv Res. 2015;15:41.

8. Saxena S, Hanna F. Dignity-a fundamental principle of mental health care. Indian J Med Res. 2015;142(4):355-358.

9. Schröder A, Ahlström G, Larsson BW. Patients' perceptions of the concept of the quality of care in the psychiatric setting: a phenomenographic study. J Clin Nurs. 2006;15(1):93-102.

10. SCIE Social Care Institute for Excellence: Protecting dignity in mental health care [homepage on the Internet]; 2015. Available from: http:// www.scie.org.uk/publications/guides/guide15/specialistcare/mentalhealth/protectingdignity.asp. Accessed July 1, 2017.

11. Bramesfeld A, Wedegärtner F, Elgeti H, Bisson S. How does mental health care perform in respect to service users' expectations? Evaluating inpatient and outpatient care in Germany with the WHO responsiveness concept. BMC Health Serv Res. 2007;7:99.

12. Robison D, McInnis-Perry G, Weeks LE, Foley V. Dignity in older adults with schizophrenia residing in assisted living facilities. J Psychosoc Nurs Ment Health Serv. 2018;56(2):20-28.

13. Grassi L, Mezzich JE, Nanni MG, Riba MB, Sabato S, Caruso R. A person-centred approach in medicine to reduce the psychosocial and existential burden of chronic and life-threatening medical illness. Int Rev Psychiatry. 2017;29(5):377-388.

14. Niveau G. Preventing human rights abuses in psychiatric establishments: the work of the CPT. Eur Psychiatry. 2004;19(3):146-154.

15. Chambers M, Gallagher A, Borschmann R, Gillard S, Turner K, Kantaris X. The experiences of detained mental health service users: issues of dignity in care. BMC Medical Ethics. 2014;15:50.

16. Mayers P, Keet N, Winkler G, Flisher AJ. Mental health service users' perceptions and experiences of sedation, seclusion and restraint. Int $J$ Soc Psychiatry. 2010;56(1):60-73.

17. Lakeman R. Leave your dignity, identity, and day clothes at the door: the persistence of pyjama therapy in an age of recovery and evidencebased practice. Issues Ment Health Nurs. 2011;32(7):479-482.

18. Skorpen F, Thorsen AA, Forsberg C, Rehnsfeldt AW. Suffering related to dignity among patients at a psychiatric hospital. Nurs Ethics. 2014; 21(2):148-162.

19. Rose D, Evans J, Laker C, Wykes T. Life in acute mental health settings: experiences and perceptions of service users and nurses. Epidemiol Psychiatr Sci. 2015;24(1):90-96.

20. Lilja L, Hellzén O. Former patients' experience of psychiatric care: a qualitative investigation. Int $J$ Ment Health Nurs. 2008;17(4): 279-286.

21. Mental Health Act Commission. Annual Report and Accounts 2008/2009 [homepage on the Internet]. Available from: https:// www.gov.uk/government/uploads/system/uploads/attachment_data/ file/250492/0630.pdf/. Accessed July 2, 2017.

22. Campbell P. Looking at ordinary people's tales of living with their mental illness. Interview by Alita Howe. Ment Health Today. 2010;2:38.

23. Curtice MJ, Exworthy T. FREDA: a human rights-based approach to health care. Psychiatrist. 2010;34:150-156.

24. Chochinov HM, Hassard T, McClement S, et al. The patient dignity inventory: a novel way of measuring dignity-related distress in palliative care. J Pain Symptom Manage. 2008;36(6):559-571.

25. Chochinov HM. Dignity-conserving care-a new model for palliative care: helping the patient feel valued. JAMA. 2002;287(17):2253-2260.

26. Chochinov HM. Dignity and the essence of medicine: the A, B, C, and D of dignity conserving care. BMJ. 2007;335(7612):184-187.

27. Albers G, Pasman HR, Rurup ML, de Vet HC, Onwuteaka-Philipsen BD. Analysis of the construct of dignity and content validity of the patient dignity inventory. Health Qual Life Outcomes. 2011;9:45. 
28. Ripamonti CI, Buonaccorso L, Maruelli A, et al. Patient dignity inventory (PDI) questionnaire: the validation study in Italian patients with solid and hematological cancers on active oncological treatments. Tumori. 2012;98(4):491-500.

29. Sautier LP, Vehling S, Mehnert A. Assessment of patients' dignity in cancer care: preliminary psychometrics of the German version of the Patient Dignity Inventory (PDI-G). J Pain Symptom Manage. 2014;47(1): 181-188.

30. Rullán M, Carvajal A, Núñez-Córdoba JM, et al. Spanish version of the patient dignity inventory: translation and validation in patients with advanced cancer. J Pain Symptom Manage. 2015;50(6):874.e1-881.e1.

31. Grassi L, Costantini A, Caruso R, et al. Dignity and psychosocial-related variables in advanced and nonadvanced cancer patients by using the patient dignity inventory-Italian version. J Pain Symptom Manage. 2017;53(2):279-287.

32. Kisvetrová H, Školoudík D, Danielová L, et al. Czech version of the patient dignity inventory: translation and validation in incurable patients. J Pain Symptom Manage. 2018;55(2):444-450.

33. Parpa E, Kostopoulou S, Tsilika E, Galanos A, Katsaragakis S, Mystakidou K. Psychometric properties of the Greek version of the patient dignity inventory in advanced cancer patients. J Pain Symptom Manage. 2017;54(3):376-382.

34. Abbaszadeh A, Borhani F, Rabori MR. Patient dignity in coronary care: psychometrics of the persian version of the patient dignity inventory. Br J Med Med Res. 2015;8(5):463-469.

35. Chochinov HM, Johnston W, McClement SE, et al. Dignity and distress towards the end of life across four non-cancer populations. PLoS One. 2016;11(1):e0147607.

36. Di Lorenzo R, Cabri G, Carretti E, et al. A preliminary study of patient dignity inventory validation among patients hospitalized in an acute psychiatric ward. Neuropsychiatr Dis Treat. 2017;13:177-190.

37. Hamilton M. A rating scale for depression. J Neurol Neurosurg Psychiatry. 1960;23:56-62.

38. Hamilton M. The assessment of anxiety states by rating. $\mathrm{Br} J \mathrm{Med}$ Psychol. 1959;32(1):50-55.

39. Aas IH. Guidelines for rating Global Assessment of Functioning (GAF). Ann Gen Psychiatry. 2011;10:2.

40. Lora A, Bai G, Bianchi S, et al. The Italian version of HoNOS (Health of the Nation Outcome Scales), a scale for evaluating the outcomes and the severity in mental health services. Epidemiol Psichiatr Soc. 2001;10(3):198-204.

41. Bryant FB, Yarnold PR. Principal components analysis and exploratory and confirmatory factor analysis. In: Grimm G, Yarnold RR, editors. Reading and Understanding Multivariate Statistics. Washington, DC: American Psychological Association; 1995:99-136.
42. Folstein MF, Folstein SE, McHugh PR. "Mini-mental state". A practical method for grading the cognitive state of patients for the clinician. J Psychiat Res. 1975;12(3):189-198.

43. Cureton EE, D'Agostino RB. Factor Analysis: An Applied Approach. 1st ed. Hillsdale, NJ: Lawrence Erlbaum Associates; 1983.

44. Kaiser HF. The varimax criterion for analytic rotation in factor analysis. Psychometrika. 1958;23(3):187-200.

45. Kaiser HF. An index of factorial simplicity. Psychometrika. 1974; 39(1):31-36.

46. Bentler PM. Factor simplicity index and transformations. Psychometrika. 1977;42(2):277-295.

47. Kaiser HF. The application of electronic computers to factor analysis. Educ Psychol Meas. 1960;20:141-151.

48. Acock AC. A Gentle Introduction to Stata. 3rd ed. College Station, TX, USA: Stata Press; 2010.

49. StataCorp. Stata Statistical Software: Release 12. College Station, TX, USA: StataCorp LP; 2011.

50. Ministero del Lavoro, della Salute e delle Politiche Sociali. La Classificazione Delle Malattie, Dei Traumatismi, Degli Interventi Chirurgici E Delle Procedure Diagnostiche E Terapeutiche. Versione Italiana della ICD-9-CM [International Classification of Diseases, 9th Revision, Clinical Modification, 2007]. Rome, Italy: Istituto Poligrafico e Zecca dello Stato, Libreria dello Stato; 2008. Italian.

51. Lokko HN, Stern TA. Regression: diagnosis, evaluation, and management Prim Care Companion CNS Disord. 2015;17(3). eCollection 2015.

52. Babalola O, Gormez V, Alwan NA, Johnstone P, Sampson S. Length of hospitalization for people with severe mental illness. Cochrane Database Syst Rev. 2014;1:CD000384.

53. Di Lorenzo R, Sagona M, Landi G, Martire L, Piemonte C, Del Giovane C. The revolving door phenomenon in an Italian Acute Psychiatric Ward: A 5-year retrospective analysis of the potential risk factors. J Nerv Ment Dis. 2016;204(9):686-692.

54. Jacobson N. A taxonomy of dignity: a grounded theory study. BMC Int Health Hum Rights. 2009;9:3

55. Lothian K, Philp I. Maintaining the dignity and autonomy of older people in the healthcare setting. BMJ. 2001;322(7287):668-670.

56. Rullán M, Arantzamendi M, Carvajal A, Martínez M, Saenz de Ormijana A, Centeno C. The patient dignity inventory: just another evaluation tool? Experiences with advanced cancer patients. Palliat Support Care. 2018;16(1):73-79.

57. Beach MC, Sugarman J, Johnson RL, Arbelaez JJ, Duggan PS, Cooper LA. Do patients treated with dignity report higher satisfaction, adherence, and receipt of preventive care? Ann Fam Med. 2005; $3(4): 331-338$
Neuropsychiatric Disease and Treatment

\section{Publish your work in this journal}

Neuropsychiatric Disease and Treatment is an international, peerreviewed journal of clinical therapeutics and pharmacology focusing on concise rapid reporting of clinical or pre-clinical studies on a range of neuropsychiatric and neurological disorders. This journa is indexed on PubMed Central, the 'PsycINFO' database and CAS,

\section{Dovepress}

and is the official journal of The International Neuropsychiatric Association (INA). The manuscript management system is completely online and includes a very quick and fair peer-review system, which is all easy to use. Visit http://www.dovepress.com/testimonials.php to read real quotes from published authors. 